\title{
Implementing professional development in invitational education
}

\author{
G. M. Steyn \\ School of Education \\ University of South Africa \\ steyngm1@unisa.ac.za
}

\begin{abstract}
The professional development of educators is seen as an ingredient essential to creating effective schools and raising learners' performance. Since educators have the most direct contact with learners, and considerable control over what is taught and how it is taught, it is reasonably assumed that enhancing educators' knowledge, skills and attitudes is a critical step towards improving learner performance. To 'reculture' schools according to the philosophy of Invitational Education in order to increase learner performance means to develop collaborative work cultures that focus, in a sustained way, on the continuous preparation and development of educators in relation to creating favourable learning conditions for all learners. Moreover, the aim of Invitational Education is to create an entire school environment that intentionally invites success for everyone in the school. This article attempts to explain key factors that may influence the effective implementation of Invitational Education as an example of professional development for educators. The following major categories are described: learning styles of educators; educators' commitment to change; transformational leadership; outof-school conditions; in-school conditions; and requirements of programmes.
\end{abstract}

Keywords: Educators' development, Inviational education, Professional development.

\section{Introduction}

Professional development has attracted a great deal of attention in recent years because of its potential for enhancing quality and learner performance (Burke 1997, 299; Browell 2000, 57). Since educators have the most direct contact with learners, and considerable control over what is taught and how it is taught, it is reasonably assumed that enhancing educators' knowledge, skills and attitudes is a critical step towards improving school quality and learner performance (King and Newman 2001, 86). The 
ultimate aim of professional development is increased learner performance, but individual learner outcomes and how educators teach learners are profoundly affected by the school culture in which educators work (King and Newman 2001, 87). This implies the need for professional learning communities in which educators and leaders work together and focus on student learning (Purkey and Strahan 1995, 4; Sparks 2003a, 29; Sparks 2003c, 55). However, individual factors, factors that are external to the school and Professional Development itself could also play an important role in creating learning communities. From this perspective designing a professional development programme should be grounded not on an abstraction in the way educators learn, but in consideration of the factors that could influence the effective implementation of any professional development programme.

Professional development of educators is seen as an essential ingredient for creating effective schools, promoting the delivery of education and development, and improving learners' performance (Rhodes and Houghton-Hill 2000, 424; Wood and Millichamp 2000, 513; Birman, Desimone, Porter and Garet 2000, 32). Since educators have the most direct contact with learners as well as considerable control over what is taught and how it is taught, it may be assumed that enhancing educators' knowledge, skills and attitudes is a critical step towards improving learner performance (King and Newman 2001, 87; Ribisch 1999, 121; Anonymous 2001/2002, 17).

The concept culture of learning and teaching is widely used in the South African education context. It refers to the attitude of educators and learners to learning and teaching, as well as their spirit of dedication and commitment to the schools (Lethoko $1999,12)$. The breakdown of the culture of learning and teaching in schools may partly be understood in terms of general organisational breakdown (Christie 1998, 293). It manifests itself in the disruption of classes, the malfunctioning of management, the collapse of authority in schools and the disruption of disciplined learning and teaching. In contrast to these schools, several of schools in South Africa are in the process of implementing Invitational Education principles. There are currently three schools that have succeeded in receiving the Inviting School Award from the International Alliance for Invitational Education by successfully applying the principles of Invitational Education. There are also a number of other schools striving to become inviting schools.

IE asserts that every person and everything in and around schools adds to, or subtracts from, the process of being a beneficial presences in the lives of learners. Ideally, the factors of people, places, policies, programmes and processes should be so intentionally inviting as to create an environment in which every person is cordially invited to develop intellectually, socially, physically, psychologically and spiritually.

From the above it is clear that to reculture schools to become intentionally inviting for the sake of increased learner performance means to develop collaborative work cultures that focus, in a sustained way, on the continuous preparation and professional development of educators in relation to creating and assessing learning conditions for all learners (Bernauer 2002, 90; Fullan in Robinson and Carrington 2002, 240). Since the school organisation acutely influences learner outcomes and teaching practices, 
professional learning should be two-pronged. It should consider not only the way individual educators learn, but also reflection and development in the way the school as an organisation influences learner performance and educators' learning and practice (Robinson and Carrington 2002, 240). Invitational Education as an example of a suitable professional development programme is maintained by the Alliance for Invitational Education as a means of transforming classrooms and climates in schools (Asbill and Gonzalez 2000, 24).

The main research question described in this article is: What factors may influence the effective implementation of Invitational Education as an example of a professional development programme for educators? The purpose is to explore the factors required for the effective implementation of a professional development programme on Invitational Education. As such it is necessary to focus on professional development as the means to implement Invitational Education. If educational discourse in this area is to advance educational practice, it is necessary for the context of relevant developments to be understood and examined. In this article, these recent developments are investigated by means of literature. To understand this question, it is necessary to provide a brief explanation of Invitational Education.

\section{Invitational Education}

The philosophy of Invitational Education has been applied in over a hundred schools throughout the world, predominantly in the United States of America (US) and Canada (IAIE State/Country Coordinators 2004, 32-34; Purkey and Strahan 1995, 5). Invitational Education is a theory of practice that emanates from the self-concept theory and the perceptual tradition (Kok and van der Merwe 2002, 1; Novak and Purkey 2001, 9-10). It is deliberately directed towards broader goals than learners and their performance alone (Purkey and Strahan 1995, 1). The aim of Invitational Education is to create an entire school environment that intentionally invites success for everyone in the school (Egley 2003, 58). Survey results from 'Inviting Schools' award winners indicated that 'test scores have risen' (Research in Invitational Education 2003, 10). This was confirmed by Purkey and Juhnke's study of an Invitational Education project in the nine District of Columbia Transformation Schools (Research in Invitational Education 2004, 9). This study shows that test results of reading and mathematics were exemplary in meeting and exceeding categorical goals in three schools, others showed progress and one school received recognition for outstanding performance (Research in Invitational Education 2004, 9). Figure 1 illustrates the various components of IE, which will be explained in the following paragraphs. 


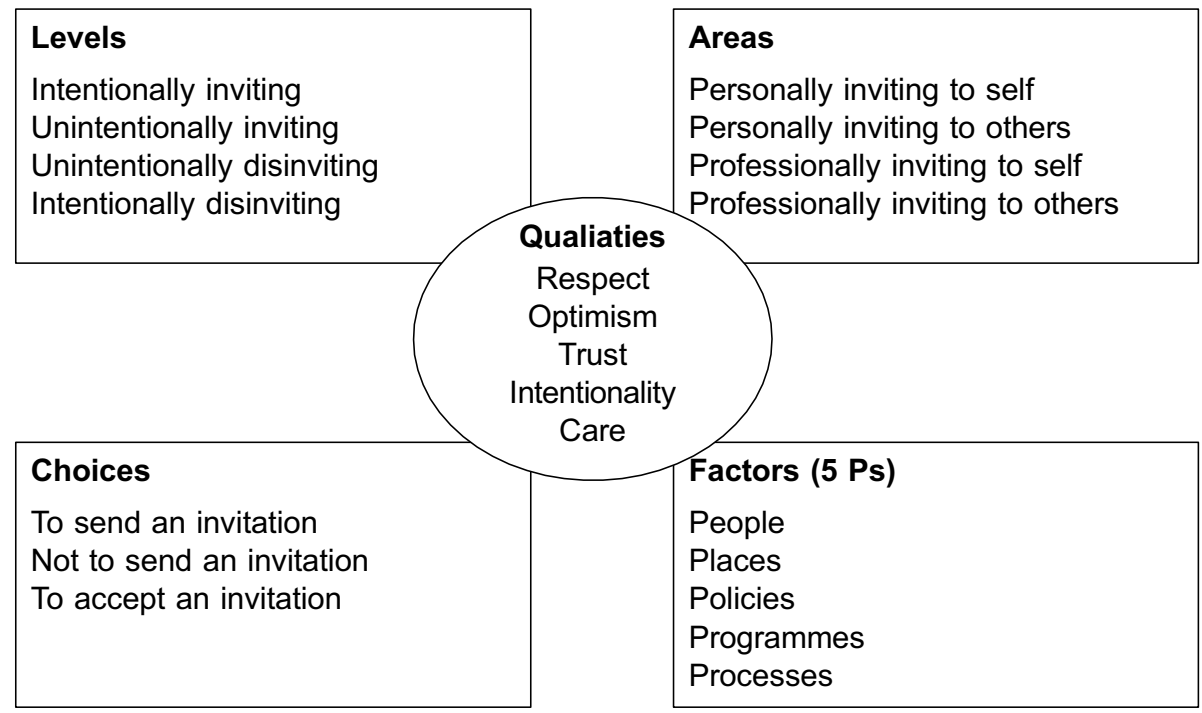

Figure 1: Components of Invitational Education

Invitational Education consists of certain key assumptions for communicating caring and appropriate messages that are intended to invite the development of human potential (Friedland 1999, 15; Kok and van der Merwe 2002, 1; Novak and Purkey 2001, 9-10; Purkey and Strahan 1995, 1). It aims to make schooling a more exciting, satisfying experience for all learners, staff, parents and the community (Purkey and Strahan 1995, 2). The theory is based on the following assumptions:

- Respect: people are able, valuable and responsible and should be treated accordingly. Invitational Education begins with the fundamental belief that all learners can succeed (Purkey and Strahan, 1995, 2). Respecting others means valuing the essential nature of human beings (Drejer 2002, 209). Everybody in the school should be viewed as able, valuable and responsible and should be treated accordingly. Respect starts with self-respect that builds integrity, uniting an individual's thoughts, feelings and actions into a new cycle of personal empowerment (Drejer 2002, 207). Selfrespect leads to respect for others, which is a principle of harmony in many traditions (such as ubuntu in African tradition) (Drejer 2002, 208). A change in a person's attitude can begin a new cycle of respect, transforming the energies in and around people. Authentic respect has the potential to empower people (Drejer 2002, 209).

Respect is transmitted by the way people communicate (Drejer 2002, 209). Shared responsibilities, based on mutual respect, form an indispensable element in inviting

* To whom correspondence should be addressed 
schools (Friedland 1999, 15). Sharing responsibilities implies that all programmes, procedures and policies in schools should be analysed to ensure that this is taking place (Brinson 1996, 85; Friedland 1999, 15).

- Trust: education is a collaborative, cooperative activity. Education should involve all staff members and learners so that they feel empowered (Friedland 1999, 145). Constantly controlling learners and staff is contrary to their developmental needs and creates a 'disinviting' climate (Brinson 1996, 85; Friedland 1999, 15). Interpersonal communication enhances an atmosphere of trust in which people share information and work together to promote organisational effectiveness (Drejer 2002, 209).

- Optimism: people possess untapped potential in all areas of development. In order to be optimistic about what each learner can become, educators should create places, policies, programmes and processes to nurture everybody - allowing them to develop their unlimited potential (Friedland, 1999:16; Kitchens, 1998:38). William Mitchell, superintendent in a school district in South Carolina had difficulties improving the academic performance of learners, until he launched a programme called 'Power of Positive Students' (POPS) that focused on building more positive attitudes and stronger self-esteem (Friedland, 1999:16). When these important human qualities became the aim, the academic and social levels of learners increased tremendously.

- Intentionality: human potential is best realised by places, policies, processes and programmes that are specifically designed to invite development and are designed by people who are personally and professionally inviting to themselves and others. Invitational staff members intentionally work to advance learning environments characterised by both purpose and direction (The Concept of Invitational Education 1998, 39; Friedland 1999, 15; Novak and Purkey 2001, 15). Unfortunately, many other reform initiatives ignore the people involved and concentrate on the systems in which they work (Brinson 1996, 81).

- Care: the process is the product in making. According to Invitational Education, means and ends are interrelated and cannot be separated in behaviour (Novak and Purkey 2001, 14). In Invitational Education care is the continuous desire to fuse means with ends. Furthermore, the research of Patterson and Patterson $(2004,75)$ shows that educators and learners are most productive when they work in a caring, supportive and trusting environment.

These assumptions of Invitational Education (outlined above) provide a guiding theory for school development, although Novak and Purkey $(2001,16)$ regard Invitational Education as a practice that is still emerging. There are five areas in which Invitational Education has to be applied, the '5 Ps': people, places, policies, programmes and processes (see Figure 1). These 5 Ps provide a framework for school development (Purkey and Strahan 1995, 4). They are the following (Novak and Purkey 2001, 17-18): 
- People: People create and maintain interpersonal behaviours in the school. The relationships of the adults who inhabit a school have more to do with the school's quality and character and with the accomplishments of its learners, than any other factor.

- Places: The aesthetic environment sends powerful messages to all the people in the school.

- Policies: These refer to all the rules, procedures and codes that are used to manage the school in an inviting way.

- Programmes: These refer to curricular, extra-curricular, informal or formal programmes implemented to inculcate learning and development.

- Processes: This $\mathrm{P}$ is the democratic coordinator of the other Ps.

As mentioned before, Invitational Education is a philosophy and a set of activities aimed at promoting a total school climate that is welcoming; a setting that intentionally energises people to realise their individual and collective potential (Friedland 1999, 14; Purkey and Strahan 1995, 2; The Concept of Invitational Education 1998, 39). Invitational Education also asserts that every person and everything in and around schools add to, or subtract from, the process of being a beneficial presence in the lives of learners. Ideally, the factors of people, places, policies, programmes and processes should be intentionally inviting so as to create an environment in which every person is cordially invited to develop intellectually, socially, physically, psychologically and spiritually. This is done by quantifying each of the P-categories according to 'disinviting' and 'inviting' guidelines (Friedland 1999, 14). Such invitations, through communication, may be unintentionally inviting, unintentionally 'disinviting', intentionally 'disinviting' or intentionally inviting - which may have a crucial effect on the development of people's human potential (see Figure 1).

For schools to become intentionally inviting, they need to implement an effective professional development programme. This implies the identification of factors that should be considered for designing professional development programmes on IE.

\section{What is professional development?}

All professions require continuous updating of knowledge and skills (Sparks and Richardson, 1997, 2; Somers and Sikorova 2002, 103). The teaching profession is no exception (Sparks and Richardson 1997, 2). Professional development helps educators to acquire the most up-to-date knowledge of the subjects they teach and of techniques that are powerful in enhancing student learning, such as Invitational Education (Browell 2000, 59; Novak and Purkey 2001, 28; Rhodes and Houghton-Hill 2000, 424; Sparks and Richardson 1997, 3). Educators will not change the way they teach, unless they learn new ways to teach (Sparks and Richardson 1997, 3).

Professional development is concerned with the continuous updating of professional knowledge and skills throughout a staff member's career, requiring self- 
direction, self-management and a sensitivity to development opportunities offered at work (Browell 2000, 57). It focuses on the knowledge, skills and attitudes required of educators, leaders and other school staff to enable them to assist all learners to learn and to develop their human potential (Ho-Ming and Ping-Yan 1999, 39; Somers and Sikorova 2002, 103; Sparks and Richardson 1997, 2).

Day (in Evans 2002, 128) defines professional development as the process by which educators review, renew and extend their commitment as change agents to the moral purposes of teaching (including IE); the process by which they develop the necessary knowledge, skills and practice in conjunction with learners and colleagues throughout their career. A goal in Invitational Education is to inspire staff members to develop four basic dimensions of their lives (see Figure 1):

- Personally inviting oneself: It is vital for educators to care for themselves in order to have a beneficial long-term presence in the lives of others (Novak and Purkey 2001, 26). This covers all personal areas outside work life, such as their mental, psychological and physical wellbeing, and entails keeping these areas developing and 'healthy'.

- Personally inviting others: Caring about others is fundamental to IE, which implies that educators should develop co-operative and harmonious relationships with people in all walks of life (Novak and Purkey 2001, 26).

- Professionally inviting oneself: The skills of educators are subject to deterioration over time and developments in educational thinking can render the skills of educators out of date or inefficient (Campbell 1997, 27). There is therefore a need for professionals to be continually involved in a quality programme of self-development. Furthermore, the responsibility of each staff member involves more than keeping up to date (Dixon 1998, 164). Their responsibility is to continually experiment, deliberately reflect on what has happened as a result of the individual or team effort, and reflect with others on the action of the whole system in order to learn how to improve. It is difficult for learners to attain high levels of learning unless members of staff are continuously learning (Sparks and Richardson 1997, 2). Professional development of individual educators is seen as an ongoing process whereby educators develop a greater sense of collaboration, share common problems and assume greater responsibility for their own professional development (Bernauer 2002, 90; Browell 2000, 59; Ribisch 1999, 116). It is important to know that educator learning and student learning go hand in hand (Sparks and Richardson 1997, 2; Wood and Millichamp 2000, 499).

- Professionally inviting others. Professional development encourages staff to aspire to improved performance in the workplace (Browell 2000, 59). Invitational Education, in particular, is about creatively and cordially requesting people to develop their full potential (Novak and Purkey 2001, 28). In inviting others, educators use their knowledge and skills to encourage learners to become lifelong learners and to enjoy learning. Moreover, according to Fullan (in Sparks 2003c, 
57), the single factor that is common to effective change is that relationships improve - a value that is also supported by Invitational Education. When this happens, schools get better (Sparks 2003c, 57). If relationships are poor, ground is lost. Invitational Education seeks to assist people and their relationships with others (Brinson 1996, 91).

Considering the above, it is realised that professional development relates to lifelong development programmes that focus on a wide range of educators' knowledge, skills and attitudes in four dimensions so that they will be more effective at inviting learners' development. There are, however, certain factors that may influence the effective implementation of professional development programmes, in particular that of Invitational Education which is the focus of the article.

\section{Factors influencing professional development in Invitational Education}

The growing body of research on professional development provides consistent guidelines for planning and implementing professional development that may lead to the improvement of practice. A crucial question is: What factors play a role in the effective implementation of professional development programmes on Invitational Education in schools? Figure 2 provides an outline of some factors that will influence the effectiveness of such a professional development programme. The following major categories are identified: learning styles of educators; educators'commitment to change; transformational leadership; personal factors; out-of-school conditions; in-school conditions; and requirements of a professional development programme. The following paragraphs briefly describe how each of these categories impacts on professional development.

Educators play a major role in professional development (Washington 1993, 253). The active involvement of staff in professional development requires a new way of thinking and interacting, and is a step in the direction of educator empowerment. Since, in effect, professional development as part of Invitational Education means that staff are learning and developing new knowledge, skills and attitudes for the sake of enhancing learner performance, such programmes should consider the learning styles of individual staff members. 


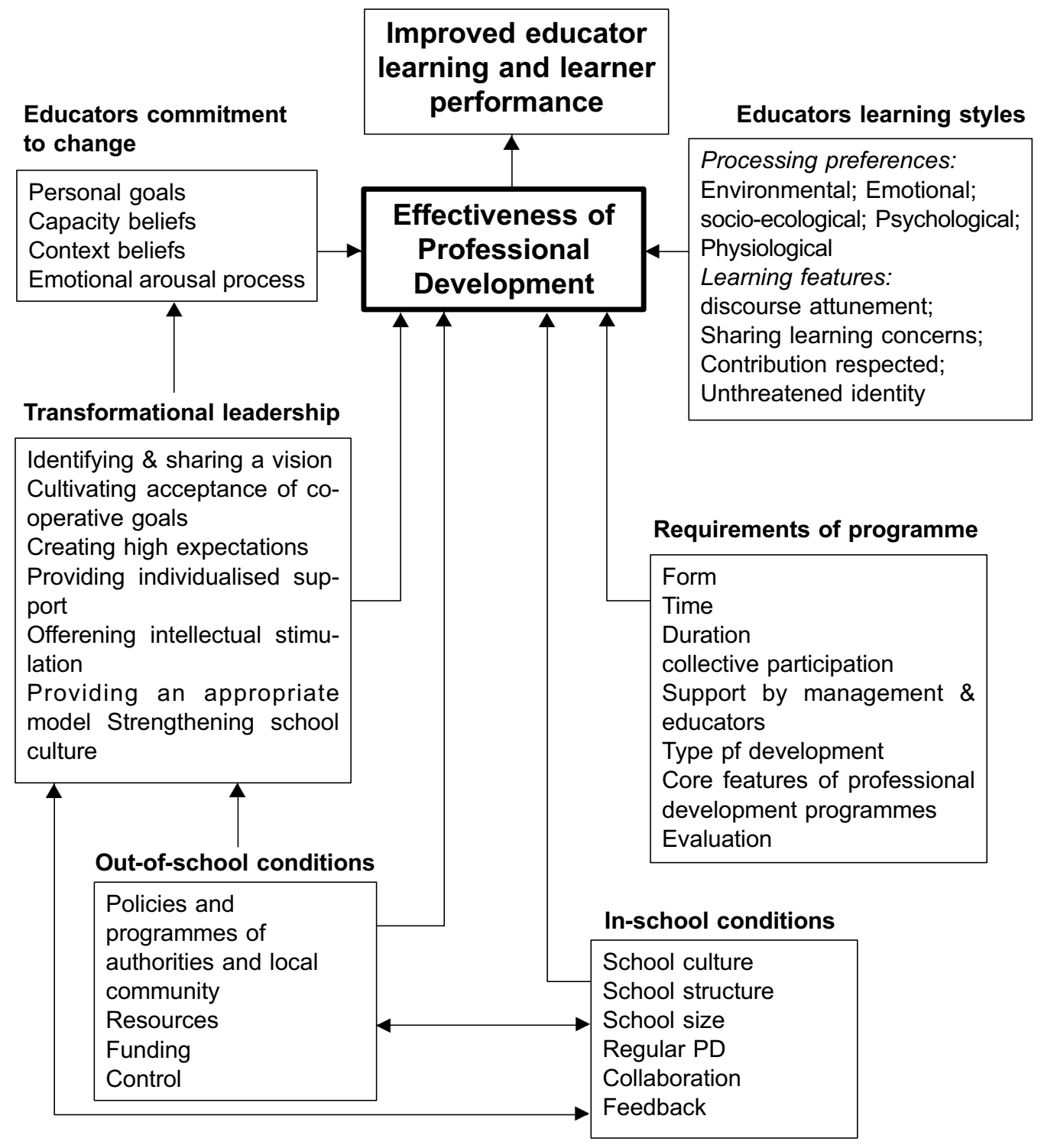

Figure 2: Factors influencing the professional development of educators

\subsection{Learning styles of educators}

To ensure effective professional development, the different learning styles of participants should be identified (Burke 1997, 299). For invitational education, this implies personalising development sessions and taking learning styles into consideration during development sessions (Vincent and Ross 2001, 42). Educators are individuals 
with specific learning needs and learning styles (Robinson and Carrington 2002, 240; Somers and Sikorova 2002, 108). Educators who learn in programmes that accommodate their preferences will acquire more skills, become more motivated and use what they learn in the classroom (Burke 1997, 301).

Learning styles include a number of variables, such as the individual's environmental, emotional, socio-ecological, psychological and physiological processing preferences (see Figure 2):

- Environmental factors. Environmental factors include a comfortable and wellequipped venue for professional development (Burke 1997, 300; Ribisch 1999, 119).

- Emotional factors. Since adults prefer to be involved in their own learning for the sake of personal ownership, they should participate in setting the goals, priorities and processes of Professional Development (Badley 1992, 17; Bernauer 2002, 91; Burke 1997, 300; Ho-Ming and Ping-Yan 1999, 36). Educator learning is most likely to occur when professional development as part of Invitational Education provides continuous opportunities for educators to be involved in the process of development, to experiment and to receive constructive feedback on particular innovations (Robinson and Carrington 2002, 240; Moore 2000, 14).

- Sociological factors. According to Burke (1997, 300) and Ribisch (1999, 117), effective profession development means maximising staff interaction through small group discussions that can stimulate their learning and provide motivation. Through a process of collaborating with professionals within and outside their schools in order to gain expertise from research, educators' learning experiences are enhanced (Bernauer 2002, 91; Ho-Ming and Ping-Yan 1999, 36; Robinson and Carrington 2002, 240). In Tyrell's view (2000:16), educators do not want to be lectured but prefer to be inspired by observing an expert performing a task.

- Physiological factors. Learning styles are also related to physiological factors: auditory (hearing), visual (seeing) and kinaesthetic (touching) (Vincent and Ross 2001, 41). Staff developers should therefore design auditory, visual, tactile, and kinaesthetic materials, and match them to each learner's strengths (Burke 1997, 300; Vincent and Ross 2001, 41).

Apart from the variables listed above, Ashworth (in Smith and Coldron 1999, 255) identifies four key features of learning:

1. Attunement to others' discourse. The way in which educators participate in Invitational Education professional development programmes from the standpoint of their own backgrounds should be acknowledged (Smith and Coldron 1999, 255; Somers and Sikorova 2002, 108). The background of individual educators includes the tradition in their particular school and the subject they are teaching, and their personal beliefs and values (Smith and Coldron 1999, 255). It is most likely that educator learning occurs when professional development on Invitational Education takes the diverse needs of learners in the specific context of their classrooms into 
account (Bernauer 2002, 91; Guskey 2002, 50; Ho-Ming and Ping-Yan 1999, 36; Mashile 2002, 174; Robinson and Carrington 2002 240; Sachs 1999, 26; Somers and Sikorova 2002, 108).

2. Sharing emotionally in concerns relevant to learning. An essential feature of participation is that individuals see themselves as having the right to voice their opinions and to be listened to (Smith and Coldron 1999, 255; Somers and Sikorova 2002, 104).

3. Being assured that they can contribute appropriately and worthily. Respect is an inviting stance of Invitational Education and, therefore, participants should feel that they are respected for what they know and can do (Smith and Coldron 1999, 255; Somers and Sikorova 2002, 104).

4. Being relatively unthreatened as regards one's identity. Many educators who are faced with changes in their teaching may feel that their threshold of competence is threatened because they have to adjust their methods. For some, this can be a source of growth. Support and sensitivity are, however, needed from those initiating the process of Invitational Education (Smith \& Coldron, 1999:255).

It is clear from the above that different contexts and different learning styles may require different techniques (Guskey 2002, 50; Professional staff development: a key to school improvement 1999, 388). Professional development programmes on Invitational Education should therefore be individualised to the extent that they build on each educator's experience and expertise, while also providing the basic knowledge required by developing professionals to succeed and become inviting (Partee and Sammon 2001, 15).

Since professional development programmes on Invitational Education also focus on educators' learning, one may deduce that educator commitment will play a crucial role in their development (Bernauer 2002, 90; Blackmore 2000, 3; Pehkonen and Törner 1999, 262; Yu, Leithwood and Jantzi 2000, 369).

\subsection{Educator commitment}

The educators' commitment is as important as the school's (if not more so) for the success of professional development and Invitational Education (Blackmore 2000, 3; Ho-Ming and Ping-Yan1999, 38; Pehkonen and Törner 1999, 262). According to HoMing and Ping-Yan (1999:38), professional development will be futile without educators' wholehearted commitment - even if such programmes are well-designed.

As discussed previously, being professionally inviting to oneself and to others represents two important dimensions of Invitational Education. Yu, Leithwood and Jantzi $(2000,369)$ describe the different aspects of educators' commitment to develop professionally as follows (see Figure 2):

- Personal goals. Personal goals provide an important source of educator commitment which should be acknowledged by educators in order to energise action. 
- Capacity beliefs. These beliefs refer to psychological states (such as self-efficacy, self-confidence, academic self-concept and aspects of self-esteem) and are supported by Invitational Education (Novak and Purkey 2001, 10). The study by Lam and Pang $(2003,90)$ shows that when educators are confident about themselves, they are more prepared to be involved in learning and development.

- Context beliefs. These refer to whether the school environment (such as the school governance structure) will provide funds, professional development or other resources for educators to effectively implement changes in their classroom practices. Schools that already have environments that reveal inviting practices can more easily become intentionally inviting.

- Emotional arousal process. The functions of this process are to create a state of readiness, to activate immediate action and to maintain action.

Law (in Rhodes and Houghton-Hill 2000, 432) suggests a model for exploring the relationship between staff commitment to professional development and leadership. According to him, a collaborative culture in schools is conducive to both the professional development of educators and the facilitation of learner achievement (Rhodes and Houghton-Hill 2000, 432). A collaborative environment is also supported by one of the assumptions of Invitational Education. Yu, Leithwood and Jantzi's model (2000, 369) of educators' commitment to change explicitly identifies the effect of leadership on educator commitment.

\section{Leadership}

The research done by Patterson and Patterson $(2004,75)$ reveals that leadership plays a significant role in establishing the overall health of a school. Campbell $(1997,27)$ and Asbill and Gonzalez $(2000,16)$ confirm this by stating that leadership is overwhelmingly important in establishing a positive environment. When principals choose to behave in an inviting manner, as advocated by invitational education, the school climate will be enhanced and total school settings will be positively transformed (Asbill and Gonzalez 2000, 25; Campbell 1997, 27). There is a positive relationship between a principal's actions and an educator's affective outcomes, such as feelings of trust, respect, job satisfaction, empowerment and perceived principal effectiveness (Asbill and Gonzalez 2000, 14; Bjork 2000, 26; Campbell 1997, 27; Edwards, Green and Lyons 2002, 68; Mahoney 1998, 98). Mahoney $(1998,96)$ says, 'successful leaders are able to commit people to action.'

Transformational leadership involves a special kind of leader-follower relationship, in which the leader can make 'ordinary people do extraordinary things in the face of adversity' (Greenberg and Baron 1993, 470). It changes people's attitudes, values and beliefs - making them less self-centred and more altruistic, which are values also 
advocated by Invitational Education (Campbell 1997, 27; Novak and Purkey 2001, 12 Sergiovanni and Starratt 1993, 186). It goes beyond transacting with followers, and transforms not only the situation but also the followers (Rue and Byars 1992, 389).

The model used in the Canadian study done by Yu, Leithwood and Jantzi (2000) includes various transformational leadership dimensions that could influence educator commitment towards Invitational Education and have an effect on professional development effectiveness (Pehkonen and Törner 1999, 262). These dimensions and their usefulness are also supported by other researchers. They are (see Figure 2):

- Identifying and sharing a vision. Charisma is a characteristic that describes leaders who are able to exert a profound influence on followers, the school's performance and climate by the force of their personality, abilities, personal charm, magnetism, inspiration and emotion (Drejer 2002, 207; Dubrin and Ireland 1993, 280). Charismatic leadership also provides a vision and a sense of mission which is critical for PD effectiveness, and therefore also for Invitational Education (Mester, Visser, Roodt and Kellerman 2002, 73; Professional staff development: a key to school improvement 1999, 388; Richardson 2003, 401).

- Cultivating the acceptance of co-operative goals. Creating a community of educators as learners requires the cultivation of shared values and the development of an appreciation for the value of working together and caring about each other (Bernauer 2002, 90; Robinson and Carrington 2002, 241). These values are also endorsed by IE.

- Creating high performance expectations. This refers to leaders' expectations of excellence, quality and high performance on the part of educators (Anonymous 2001/ 2002, 18).

- Providing individualised support. The way in which educators are supported through the process of change - in this case, being intentionally inviting, is important (Brandt 2003, 10; Gerber 1998, 170; Richardson 2003, 401; Robinson and Carrington 2002, 239; Sachs 1999, 26). It is also important to give educators psychological and logistical support to continue developing new habits during the implementation plunge that reduces effectiveness before the new procedures become routine (Anonymous 2001/2002, 18; Pehkonen and Törner 1999, 260; Professional staff development: a key to school improvement 1999, 388; Sparks 2003b, 43; Somers and Sikorova 2002, 103; Washington 1993, 252).

- Offering intellectual stimulation. Intellectual stimulation regarding Invitational Education challenges educators to re-examine certain assumptions of their practices and to rethink how they can be accomplished (Yu, Leithwood and Jantzi 2000, 370).

- Providing an appropriate model. Personal examples of being intentionally inviting, which are consistent with the values the leaders advocate, are set for staff to follow (Yu, Leithwood and Jantzi 2000, 371).

- Strengthening school culture. It is very likely that, without effective leadership, in 
particular transformational leadership, efforts to change the school culture and influence educator commitment towards Invitational Education will fail (Bernauer 2002, 90).

Apart from the crucial effect of leadership on professional development as part of IE, the conditions within a school can feature prominently in the effectiveness of such programmes.

\section{In-school conditions}

The recognition that changing school cultures is a slow process holds true for Invitational Education too. Staff should know that the benefits of collaborative teamwork to both the learners and the other parties involved are greater than the costs in terms of time, energy and resources (Browell 2000, 62; Rhodes and Houghton-Hill 2000, 433; Shellady and Stichter 1999, 155). Working towards a more inviting, friendlier and supportive school environment will make the school less threatening and more rewarding (Anonymous 2001/2002, 18; Brandt 2003, 15; Friedland 1999, 14).

The Canadian study done by Yu, Leithwood and Jantzi (2000) includes mediating variables such as school culture, school structure, strategies for change and school environment, that may affect educator commitment to change. Since educator commitment will impact on professional development, one may deduce that these variables may also impact on professional development during Invitational Education. Research also reveals some other variables concerning in-school conditions, that may influence the effectiveness of professional development, including that of Invitational Education (see Figure 2).

- School culture. This refers to the norms, values, beliefs and assumptions shared by the role players of a school, which shape decision making and practices (Duff in Smith and Lowrie 1998, 7; Yu, Leithwood and Jantzi 2000, 370). The initial condition for effective professional development in Invitational Education should be a positive school culture, otherwise the staff will spend valuable time and resources in achieving only minor growth. The school culture should be humane (that is, psychologically comfortable with warm human relationships) and professionally supportive so that people can have the resources and the opportunities they need to collaborate and learn from others (Anonymous 2001/2002, 18; Brandt 2003, 15; Partee and Sammon 2001, 15; Somers and Sikorova 2002, 103).

- School structure. This variable refers to opportunities for educators to participate in decision making about classroom and school-wide practices. If the school structure supports shared and distributed leadership, then educators can believe that they are empowered to shape meaningful and feasible changes in their classrooms and in the school (Campbell 1997, 27; Washington 1993, 252).

- School size. The size of the school appears to be an important factor to planners of 
Invitational Education development programmes (Smith and Lowrie 1998, 14; Smith and Coldron 1999, 252). In larger schools where there is a large volume of staff development activity, many individual educators appear to be relatively uninvolved in development (Smith and Lowrie 1998, 14). On the other hand, in smaller schools, educators appear to be more involved. The professional background of educators and cultural norms may, however, also have an influence.

- Regular professional development. Since ongoing development is a characteristic of effective professional development, it is obvious that such programmes on Invitational Education should be presented on a regular basis.

- Collaboration. Educator collaboration and support are required for Professional Development to be effective, which is also applicable to Invitational Education (Anonymous 2001/2002, 18; Brandt 2003, 10; Rhodes and Houghton-Hill 2000, 431; Richardson 2003, 401). Unfortunately, the traditional culture of educator isolation in many schools and the limited time available for interaction within schools have not encouraged educators to cooperate as colleagues (Collinson 2001, 267; Ribisch 1999, 116; Trent 1997, 108). Professional development should therefore provide opportunities for educators to discuss their achievements and problems as they employ new strategies (Bernauer 2002, 90; Robinson and Carrington 2002, 240). In this way, the collaboration will contribute towards the development of a positive school culture that is committed to being inviting and the creation of better learning opportunities for all (Robinson and Carrington 2002, 240; Rhodes and Houghton-Hill 2000, 431).

- Feedback. An Invitational Education development programme is most effective when it is a continuous process that includes individual follow-up through supportive observation and feedback, staff dialogues, mentoring and peer coaching (Birman, Desimone, Porter and Garet 2000, 29; King and Newman 2001, 87; Lam and Pang 2003, 87; Moore 2000, 14; Richardson 2003, 401; Redding and Kamm 1999, 29; Robinson and Carrington 2002, 239).

One should realise that schools do not operate in a vacuum, but are part of a larger system in which they have to meet goals set by authorities.

\section{Out-of-school conditions}

Conditions outside schools have the potential to influence how the schools function. This can impact on professional development as part of Invitational Education in schools. Adhering to such conditions may hamper the effective implementation of Invitational Education. The following conditions are highlighted (see Figure 2):

- Policies and programmes of authorities and local community: Legislation to improve learners' abilities to succeed in school as lifelong learners and to become contributing citizens and employees in a global marketplace put principals and educators under immense pressure (Partee and Sammon 2001, 14). 
- Resources: The quality of teaching and learning depends on people and structural and technical resources, which are influenced by the community context and the policies and programmes of other external role players (King and Newman 2001, 88). These may include human and social resources such as parent support; financial resources such as family income and school funding; technical resources such as equipment, materials and technology; organisational structures; time for educators to plan; and school bureaucracy. Schools are pressurised to 'produce more for less' and, at the same time, to achieve certain goals and standards (Robinson and Carrington 2002, 239).

- Funding: Planning for continuous professional development as part of Invitational Education implies the availability of the necessary funding.

- Control: Responding to change through professional development can keep educators seemingly busy, but makes them dependent if others control their actions (Smith and Lowrie 1998, 7). This is in contrast to empowerment, as advocated by IE, where educators take control of change processes (Edwards, Green and Lyons 2002, 68; Englehardt and Simmons 2002, 45; Richardson 1992, 287; Smith and Lowrie 1998, 7).

The preceding paragraphs outlined numerous factors that may impact on the effective implementation of professional development. However, the influential role of professional development programmes in the effective implementation of Invitational Education cannot be ignored.

\section{Requirements of programmes}

For professional development in the process of Invitational Education to be effective, certain structural factors are important (see Figure 2).

- Form: In order for Invitational Education programmes to be effective, such programmes should be longer and more content-focused, and should include active learning and coherence (Birman et al. 2000, 29).

- Time: Quick fixes for Invitational Education may not produce the desired results (Blackmore 2000, 4; Novak and Purkey 2001, 25). Educators need blocks of time without responsibilities for optimal learning to take place (Professional staff development: a key to school improvement 1999, 388). Staff themselves should determine the appropriate time for professional development. To treat time as a linear, uniform concept may lead to misdirected professional development efforts and a lack of meaningful educator participation (Collinson 2001, 267).

- Duration: professional development on Invitational Education should take place over an extended period of time (Birman et al. 2000, 29; Blackmore 2000, 3; Richardson 2003, 401; Russell 2001, 3).

- Collective participation: Collective participation can contribute to a shared 
professional culture where educators develop the same values and goals regarding Invitational Education (Bernauer 2002, 90; Birman et al. 2000, 30; Cullen 1999, 46; Drejer 2000, 208). Shared learning is regarded as the key to sustaining momentum in PD (Igniting your learning approach to the method of encouraging deeper learning in your organisation 2003, 21). In the absence of such interaction, the possibility for change and development in the school is limited (Collinson 2001, 267).

- Support by management and educators: In order for programmes on Invitational Education to be effective, both leadership and educators should support them (Richardson, 2003:401).

- Type of development: The type of development on Invitational Education should be applicable to educators' practice (Shelton \& Jones, 1996:99). Outside providers often use inappropriate activities which are not geared towards classroom learning. Although it is widely acknowledged that learners learn differently, schools neglect to apply this concept to professional development and use a one-size-fits-all approach for educator development programmes (Shaw, 2003:40). Educators, like learners, may be at different stages in the mastery of certain skills.

- Core features of professional development programmes: The following features are identified:

- Content focus: Programmes on Invitational Education should be contextualised and fit for the school (Ho-Ming and Ping-Yan1999, 39; Guskey 2002, 50; Mashile 2002, 175; Sparks 1997, 21).

- Active learning: Educators should be actively involved during the presentation and obtain feedback on their inviting practices afterwards (Birman et al. 2000, 29; Blackmore 2000, 3; Moore 2000, 14; Redding and Kamm 1999, 29). Active learning encourages staff to become involved in meaningful discussions, planning and practice as part of the professional development programmes in the course of Invitational Education (Birman et al. 2000, 31).

- Coherence: Invitational Education programmes should encourage continued communication among staff (Birman et al. 2000, 29).

- Evaluation: Programme evaluation is a critical and integral part of professional development (Professional staff development: a key to school improvement 1999, 390; Russell 2001, 3; Vincent and Ross 2001, 37). One should, however, consider that evaluations of professional development programmes as part of Invitational Education do not necessarily prove whether the programme is effective or not. The relationship between professional development during Invitational Education and improvement in student learning is much too complex and includes many variables (Guskey, 2002:49).

\section{Conclusion}

For schools that wish to pursue IE, there is a need for changing deeply ingrained habits (Smith 1999, 217; Kalec 2004, 10). However, in order to make secure changes, as is 
also required for the effective implementation of Invitational Education, more than behavioural changes are required (Schein 1999, 169). This implies that role players should reframe the schooling situation, learn new concepts, and develop new attitudes and ways of feeling and thinking, or the behavioural change will not last. It also requires structural changes in the organisation of the school to support the developmental initiatives. According to Fullan (in Sparks 2003c, 57), structural obstacles often make it difficult for people to socialise and cultural obstacles cause educators to resist interacting with each other in new ways. Such problems can be addressed by professional development programmes for principals and educators, in particular towards the philosophy of Invitational Education.

A starting point would be a clear and unambiguous vision regarding Invitational Education for the school. Creating a meaningful vision helps staff to see that they are making a meaningful contribution (Smith 1999, 221). The school's approach should conform to conditions for successful development of an autonomous learning system where the most valuable asset is the school's ability to build upon its lived experience, to learn from experience and to turn in a better performance by inviting all to work out for themselves what that performance will be.

\section{References}

Anonymous 2002/2002. New staff development standards issued. Reading Today, 19 (3): 17-18.

- 1999. Professional staff development: a key to school improvement. NCA-Quarterly 73 (3): 387-391.

- Research in Invitational Education 2003. Forum 24 (1): 9,10.

- Research in Invitational Education 2004. Forum 25 (2): 8, 9.

Asbill, K. and M. L. Gonzalez. 2000. Invitational leadership: teacher perceptions of inviting principal practices. Journal of Invitational Theory and Practice 7 (1): 14-27.

Badley, G. 1992. How (not) to evaluate a staff development workshop? NASD Journal June, 27:17-22.

Bernauer, J. 2002. Five keys to unlock continuous improvement. Kappa Delta Pi Record, Winter 38 (2): 89-92.

Birman, B. F., L. Desimone, A. C. Porter and M. S. Garet. 2000. Designing professional development that works. Educational Leadership 57 (8): 28-33.

Bjork, C. 2000. Responsibility for improving the quality of teaching in Japanese schools: the role of the principal in professional development efforts. Education and Society, 18 (3): 21-43.

Blackmore, J. 2000. Developing conditions to teacher professional renewal. Teacher Learning Network Summer, 7 (1): 3-5.

Brandt, R. 2003. Is this school a learning organisation? 10 ways to tell. Journal of Staff Development 24 (1): 10-17.

Brinson, K. H. 1996. Invitational Education as a logical, ethical and democratic means to reform. Journal of Invitational Theory and Practice, Winter 4 (1): 81-94.

Browell, S. 2000. Staff development and professional education: A cooperative model. Journal of Workplace Learning 12 (2): 57-65.

Burke, K. 1997. Responding to participants' learning styles during staff development. ClearingHouse, July/August 70 (6): 299-301. 
Campbell, B. 1997. Professional development: beyond the on-day serving. The Practising Administrator 19 (2): 26-28, 35.

Collinson, V. 2001. 'I don't have enough time': Teachers' interpretations of time as a key to learning and school change. Journal of Educational Administration 39(3): 266-281.

Cullen, J. 1999. Socially constructed learning: a commentary on the concept of the learning organisation. The Learning Organisation 6(1): 45-52.

Dixon, N. M. 1998. The responsibilities of members in an organisation that is learning. The Learning Organisation 5 (4): 161-167.

Drejer, E. D. 2002. Leading the Toa: The energising power of respect. The Learning Organisation, 9(5): 206-213.

Dubrin, A. J. and R. D. Ireland. 1993. Management and organisation. 2nd ed. Cincinnati, Ohio: South-Western (College Division).

Edwards, J. L., K. E. Green and C. A. Lyons. 2002. Personal empowerment, efficacy and environmental characteristics. Journal of Educational Administration 40 (1): 67-86.

Egley, R. 2003. Invitational leadership: Does it make a difference? Journal of Invitational Education 9:57-70.

Englehardt, C. S. and P. R. Simmons. 2002. Creating an organisational space for learning. The Learning Organisation 9 (1): 39-47.

Evans, L. 2002. What is teacher development? Oxford Review of Education 28 (1): 123-137.

Friedland, S. 1999. Violence reduction? Start with school culture. School Administrator 56 (6): 1416.

Gerber, R. 1998. How do workers learn in their work? The Learning Organisation 5 (4): 168-175.

Greenberg, J. and A. Baron. 1993. Behavior in organisations: Understanding and managing the human side of work. 4th ed. Needham Heights, Mass: Boston.

Guskey, T. R. 2002. Does it make a difference: Evaluating professional development. Educational Leadership 59 (6): 45-51.

Ho-Ming, N. G. and C. Ping-Yan. 1999. School-based teacher development in Guangzhou, China. International Studies in Educational Administration 27 (2): 32-42.

IAIE State/Country Coordinators. 2004. The Invitational Education FORUM 25 (1): 32-35.

—. 2003. Igniting your learning approach: How to encourage deeper learning in your organization. Development and Learning in Organisations 17 (2): 21-23.

Kalec, A. W. 2004. Invitational Education at Cooper Elementary. Journal of Invitational Theory and Practice 10:69-76.

King, M. B. and F. M. Newman. 2001. Building school capacity through professional development: Conceptual and empirical considerations. The International Journal of Educational Management 15 (2): 86-94.

Kok, J. C. and M. P. van der Merwe. 2002. Invitational Education: Adding uniqueness - an empirical study. Paper presented at the 18th International Conference of the IAIE, Kennesaw State College, Atlanta, 10 and 12 October 2002.

Kitchens, A. 1998. Good teachers: Who are they and what can they do? Journal of Developmental Education 22 (1): 38.

Lam, Y. L. J. and S. K. N Pang. 2003. The relative effects of environmental, internal and contextual factors on organisational learning: the case of Hong Kong schools under reforms. The Learning Organisation 10 (2): 83-97.

Mahoney, J. A. 1998. The inviting school superintendent. Journal of Inviting Theory and Practice 5 (2): 97-105.

Mashile, E. 2002. Continuous professional development for teachers: The state, professional councils and higher education. South African Journal of Higher Education 16 (1): 174-182. 
Mester, C., D. Visser, G. Roodt and R. Kellerman. 2002. Leadership style and its relation to employee attitudes and behaviour. Industrial Psychology 29 (2): 72-82.

Moore, K. B. 2000. Successful and effective professional development. Scholastic Early Childhood Today 15 (3): 14-16.

Novak, J. M. and W. W. Purkey. 2001. Invitational Education. Bloomington, Ind.: Phi Delta Kappa Educational Foundation.

Partee, G. L. and G. M. Sammon. 2001. A strategic approach to staff development. Principal Leadership 1 (6): 14-17.

Patterson, J. and J. Patterson. 2004. Sharing the lead. Educational Leadership 61 (7): 74-77.

Pehkonen, E. and G. Törner. 1999. Teachers' professional development: What are the key change factors for mathematics teachers? European Journal of Teacher Education 22 (2-3): 259275.

Purkey, W. W. and D. Strahan. 1995. School transformation through Invitational Education. Researching in The Schools 2 (2): 1-6.

Redding, J. C. and R. M. Kamm. 1999. Just-in-time staff development: one step to the learning organisation. NASSP Bulletin 83 (604): 28-31.

Rhodes, C. and S. Houghton-Hill. 2000. The linkage of continuing professional development and the classroom experience of pupils: Barriers perceived by senior managers in some secondary schools. Journal of In-Service Education 26 (3): 423-435.

Ribisch, K. H. 1999. The facilitator as agent of change. ELT Journal 53 (2): 115-121.

Richardson, V. 1992. The agenda-setting dilemma in a constructivist staff development process. Teaching \& Teacher Education 8 (3): 287-300.

C. 2003. The dilemmas of professional development. Hi Delta Kappan 84 (5): 401-406.

Robinson, R. and Carrington, S. 2002. Professional development for inclusive schooling. International Journal of Educational Management 16 (5): 239-247.

Rue, L. W. and L. L. Byars. 1992. Management, skills and application. Boston, MA: Irwin.

Russell, P. 2001. Professional development: Making it effective. Teacher Learning Network 8 (3): 3-7.

Sachs, A. 1999. Solid foundation. NSDC standards are the rock of Maryland schools to build on. Journal of Staff Development 20 (1): 23, 24, 26-28.

Schein, E. H. 1999. Empowerment, coercive persuasion and organisational learning: Do they connect? The Learning Organisation 6 (4): 163-172.

Sergiovanni, T. and R. J. Starratt. 1993. Supervision: a redefinition. 5th ed. New York, NY: McGraw-Hill.

Shaw, T. 2003. Professional development potluck: successful programs offer a dish for every taste. Multimedia Schools 10 (2): 39-41.

Shellady, S. and J. P. Stichter. 1999. Training preservice and in-service educators to conduct functional assessments: initial issues and implications. Preventing School Failure 43 (4): 154-159.

Shelton, M. and M. Jones. 1996. Staff development that works! A tale of four T's. NASSP Bulletin 80 (582): 99-105.

Smith, E. and T. Lowrie. 1998. Staff development in the V.E.T. sector: case studies of two providers. Australian Journal of Teacher Education 23 (2): 5-16.

Smith, P. A. C. 1999. The learning organisation ten years on: a case study. The Learning Organisation 6 (5): 217-224.

Smith, R. and J. Coldron. 1999. Conditions for learning as teacher. Journal of In-Service Education 25 (2): 245-260.

Somers, J. and E. Sikorova. 2002. The effectiveness of an in-service education on teachers course for influencing teachers' practice. Journal of In-Service Education 28 (1): 95-114. 
G. M. Steyn

Sparks, D. 1997. A new vision for staff development. Principal, September 77 (1): 20-22.

—. 2003a. Transformational learning. Journal of Staff Development 24 (1): 29.

C. 2003b. Skill building. Journal of Staff Development 24 (1): 43.

C. 2003c. Change agent. Journal of Staff Development 24 (1): 55-59.

Sparks, D. and J. Richardson. 1997. A primer on professional development. Journal of Staff Development 18 (4): 1-8.

- The concept of Invitational Education.1998. Journal of Developmental Education 22 (1): 3839.

Trent, L. M. Y. 1997. Enhancement of the school climate by reducing teacher burnout: using an invitational approach. Journal of Invitational Theory and Practice 4 (2): 103-114.

-Tyrell, K. 2000. Professional development in education: more questions than answers. Education Review 14 (1): 14-17.

Vincent, A. and D. Ross. 2001. Personalise training: Determine learning styles, personality types and multiple intelligence online. The Learning Organisation 8 (1): 36-43.

Washington, K. R. 1993. Teacher initiated staff development: What do principals and teachers think? School Organisation 13 (3): 251-253.

Wood, E. K. and P. Millichamp. 2000. Changing the learning ethos in school. Journal of In-Service Education 26 (3): 499-515.

Yu, H., K. Leithwood and D. Jantzi. 2000. The effects of transformational leadership on teachers' commitment to change in Hong Kong. Journal of Educational Administration 40 (4): 368389. 